\title{
NUEVA EVIDENCIA SOBRE LA PRESENCIA SELKNAM TARDÍA EN LA TIERRA DEL FUEGO CHILENA
}

MATEO MARTINIC B.*

Recibido: 01/04/2008

Aceptado: 26/05/2008

\section{RESUMEN}

Se entregan antecedentes fotográficos que permiten informar con mayor precisión acerca de la que pudo ser la postrera comunidad sélknam en el sur de la isla grande de Tierra del Fuego (Chile), hacia fines de la tercera década del siglo XX. Con ello se afirma la tesis de la supervivencia histórica tardía de la etnia en suelo chileno, hasta una época indeterminada de la primera mitad del siglo XX.

PALABRAS CLAVE: Selknam, fotografía, isla de Tierra del Fuego.

\section{NEW EVIDENCE OF LATE SELKNAM PRESENCE IN CHILEAN TIERRA DEL FUEGO}

\begin{abstract}
Photographic information that allows reporting with major precision what could have been the last Selknam community in the south of Tierra del Fuego island (Chile), towards the end of the 20th century third decade, are delivered. This affirms the thesis of the historical late survival of the ethnic group in Chilean territory, up to an indeterminate epoch of the first half of the 20th century.
\end{abstract}

KEYWORD: Selknam, photography, Tierra del Fuego Island.

\section{INTRODUCCIÓN}

Hace algunos años investigamos acerca de la presencia de indígenas sélknam en la Tierra del Fuego chilena pasado 1900 y pudimos establecer, con numerosos antecedentes, que la misma se prolongó efectivamente por entre tres y cuatro décadas, tal vez hasta una época indeterminada previa a la mitad del siglo XX, hecho virtualmente desconocido por etnógrafos e historiadores. La publicación correspondiente se hizo en esta misma revista (Martinic 2003).

Intuíamos entonces que el grupo o comunidad supérstite final podía haber habitado en los campos de la antigua estancia "Vicuña", situados en general entre el paralelo $54^{\circ}$ (límite austral de la Concesión Nogueira que diera origen a la Sociedad Explotadora de Tierra del Fuego en 1893) y el lago Fagnano por el sur; la frontera internacional en el este y las estribaciones orientales de las montañas litorales del

* Profesor Emérito, Centro de Estudios del Hombre Austral, Instituto de la Patagonia, Universidad de Magallanes. Casilla de correo 113-D, Punta Arenas, Magallanes, Chile. Correo electrónico: magallania@umag.cl 
fiordo del Almirantazgo, por el oeste. Sustentaban esta suposición algunos datos un tanto imprecisos recogidos por el etnólogo P. Martín Gusinde en 1919 y 1920, y otras referencias más concretas obtenidas por el capitán de ejército Carlos Fuentes Rabé durante su recorrido por la isla en 1920. Estaban por fin las sugerentes fotografías tomadas por un fotógrafo desconocido en un indeterminado sector boscoso del sur de la Tierra del Fuego y reproducidas en la página 27 de nuestro trabajo mencionado.

La intuición tuvo su recompensa poco después cuando tuvimos la oportunidad de recibir en el Centro de Estudios del Hombre Austral a dos periodistas finlandenses, los señores Mikko Piela y Tahavo Irvonen a fines de 2003, quienes acababan de llegar a Magallanes con el propósito de repetir en parte el viaje de investigación realizado en 1929 en la isla grande de Tierra del Fuego por el geólogo Dr. Väinö Auer (1895-1981), interesado en el estudio de las turberas como depósitos sedimentarios de antiquísimas épocas. La razón de su propio interés estaba en el gran prestigio académico de que gozaba Auer en su país natal, al punto de ser tenido como una figura de eminencia pública nacional. Portaban consigo un ejemplar del libro Tulimaata tutkimasssa (Investigación en Tierra del Fuego) publicado en 1929 en lengua finesa y que hasta el presente no ha sido traducido a otro idioma, impidiéndose así virtualmente el acceso a su contenido. Pedí a mis visitantes que permitieran echarle una mirada porque observé que contenía algunas fotografías y, para mi sorpresa, una de ellas al menos mostraba a tres mujeres sélknam posando junto a uno de los ayudantes de Auer, delante de una de las casas de la estancia "Vicuña".

A partir de ese momento mi preocupación estuvo en conseguir mayor información acerca de ése y otros testimonios fotográficos de la presencia indígena tomados durante el transcurso de la expedición por suelo chileno' ${ }^{1}$. El esfuerzo tuvo su recompensa cuando finalmente (julio de 2007) llegó a nuestras manos la película documental realizada por los periodistas mencionados, en homenaje a su

1

Esta información se puso en conocimiento de la Dra. Margarita Alvarado, quien pudo obtener parte de dicho material documental y utilizarlo en su libro Fueguinos. Fotografías Siglos XIX y XX. Imágenes o imaginario del fin del mundo (Margarita Alvarado, Carolina Odone, Felipe Maturana y Dánae Fiore Editores,Pehuén Ediciones, Santiago, 2007). ilustre compatriota, trabajo en el que se incluyeron trozos del documento cinematográfico realizado por el propio Auer y del que carecíamos toda información. Es en esta película, precisamente, donde se contiene una secuencia de tomas que muestras a los indígenas en la estancia "Vicuña".

\section{ANÁLISIS DEL TESTIMONIO FOTOGRÁFICO}

De la secuencia fílmica hemos obtenido posteriormente imágenes que se presentan en el apéndice, a las que se agrega una fotografía incluida en el libro de Auer y otra obtenida de una toma reciente realizada por los periodistas.

La observación de las mismas permite valorizarlas como un testimonio fotográfico excepcional, por cuanto permite conocer sin lugar a dudas, con fecha y lugar de presencia, una auténtica comunidad familiar sélknam conformada por Freily (Figs. 1 y 6), su esposa (la mujer de edad mediana que aparece a la derecha en las figuras 2 y 3); por una adolescente acerca de la que no sabemos qué vinculación familiar podía tener con el matrimonio, y por una mujer mayor, tal vez la madre de la esposa de Freily (ambas en las figuras 4 y 5).

Observadas cuidadosamente las fotografías, cabe apreciarlas, a nuestro juicio, por dos aspectos: uno, la soltura y libertad que emana de las poses de los retratados, esto es, dándose a entender que se trató de una secuencia de tomas sin mayor preparación ni condicionamiento por parte de quien las realizó, lo que refuerza la autenticidad expresiva; y dos, precisamente esta última característica que manifiesta, según lo entendemos, una suerte de alegre satisfacción o de conformidad en el vivir, particularmente en las mujeres. Freily, en cambio, en su seriedad parece reflejar el drama étnico de otrora, del que fue testigo según lo cuenta el geólogo Auer.

2 No fue éste, es claro, el único caso conocido de trabajo indígena asalariado en la Tierra del Fuego chilena, pues a los datos entregados en nuestro primer artículo, podemos añadir ahora otro para una época tan tardía como el medio siglo XX. En efecto, según información que nos ha sido dada por el señor Eric Pettersen, antiguo alto empleado de la Sociedad Explotadora de Tierra del Fuego, quien hacia 1950 trabajaba como subadministrador de la estancia "San Sebastián", y que recuerda haber conocido allí a un indio auténtico (sélknam) que trabajaba en el establecimiento como domador. 


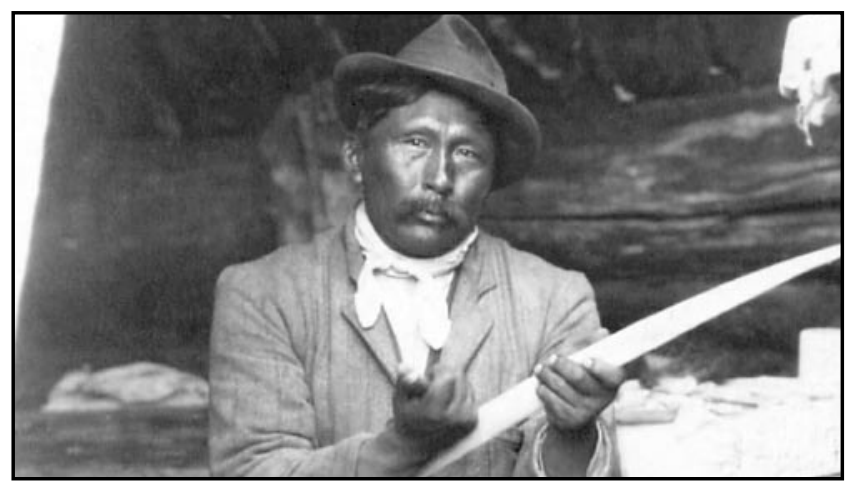

Fig. 1: Freily, trabajador de la estancia "Vicuña", jefe de la familia sélknam allí residente y guía del Dr. Väinö Auer.

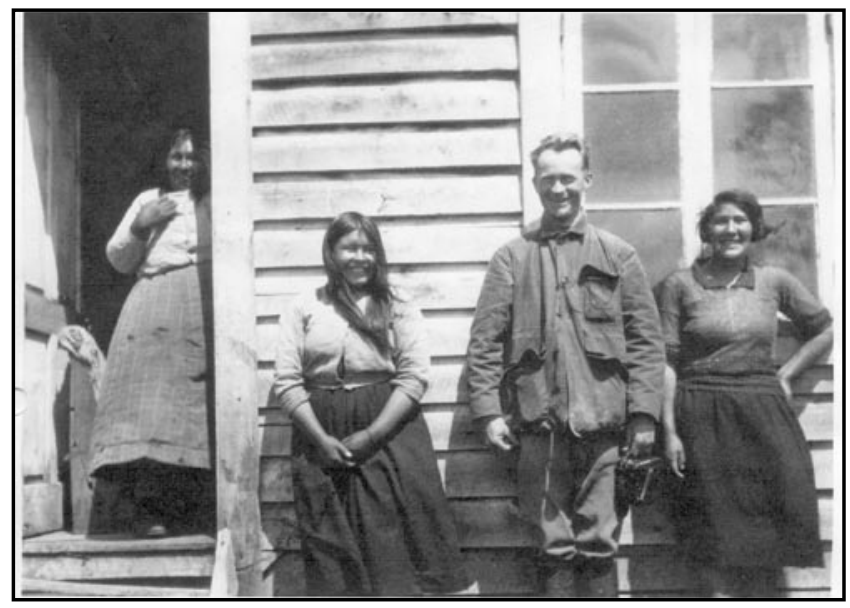

Fig. 3: Las mismas mujeres con el fotógrafo de la toma anterior.

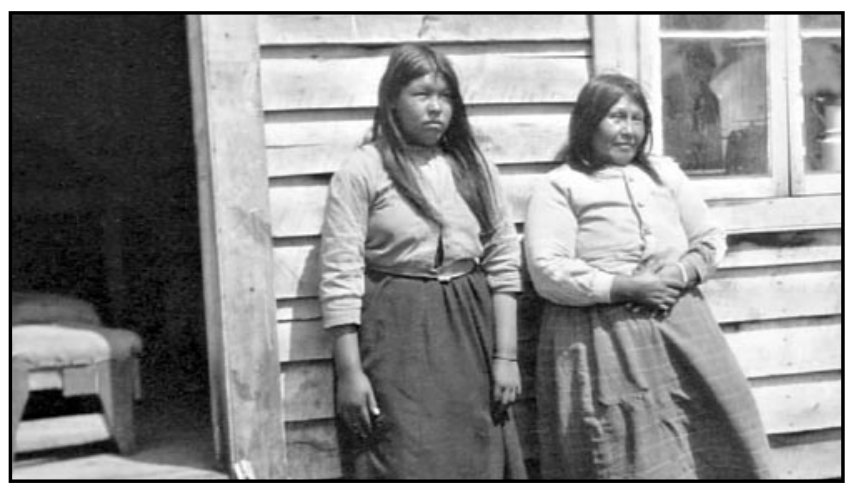

Fig.5: Las mismas mujeres de la Figura 4.

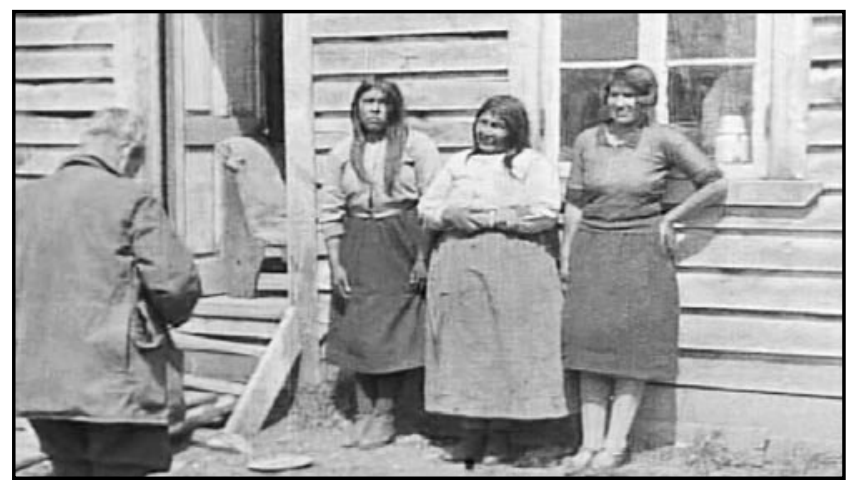

Fig. 2: Mujeres integrantes del grupo familiar sélknam de estancia "Vicuña".

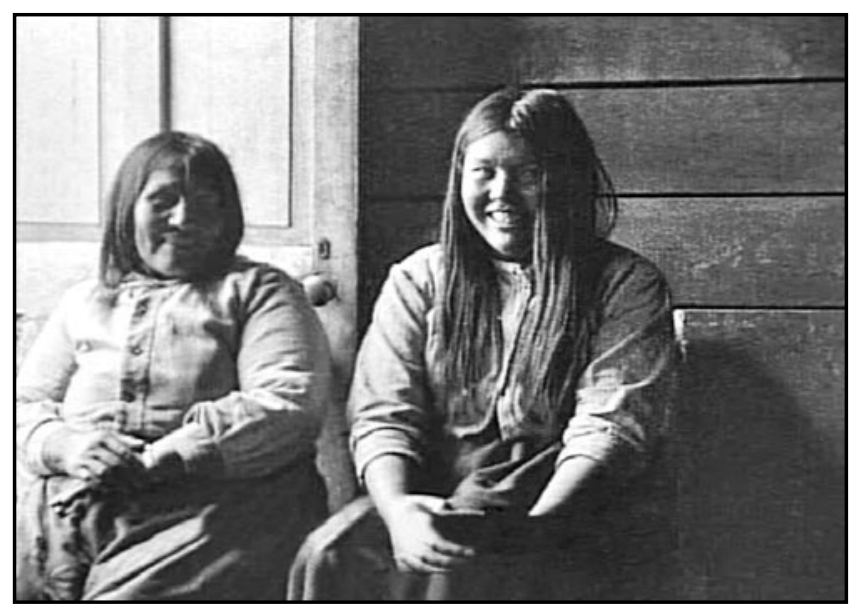

Fig. 4: La mujer mayor y la muchacha del grupo sélknam de Vicuña.

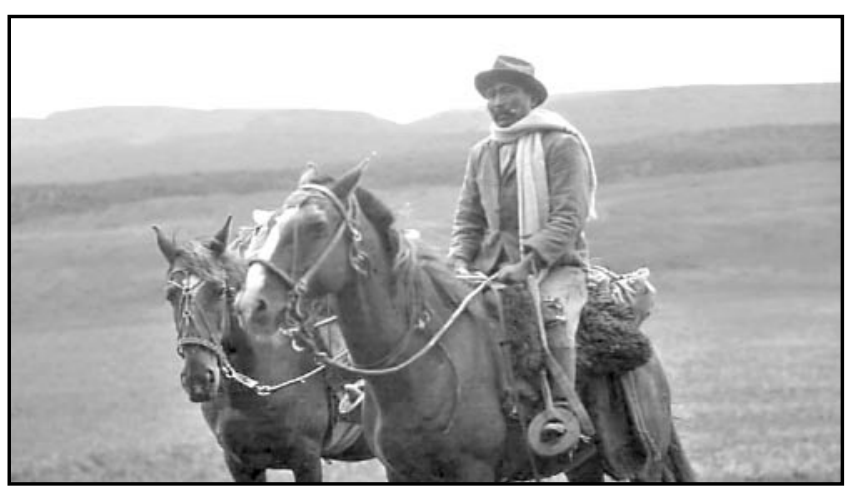

Fig. 6: Freily listo para servir de baqueano de la misión finlandesa. 


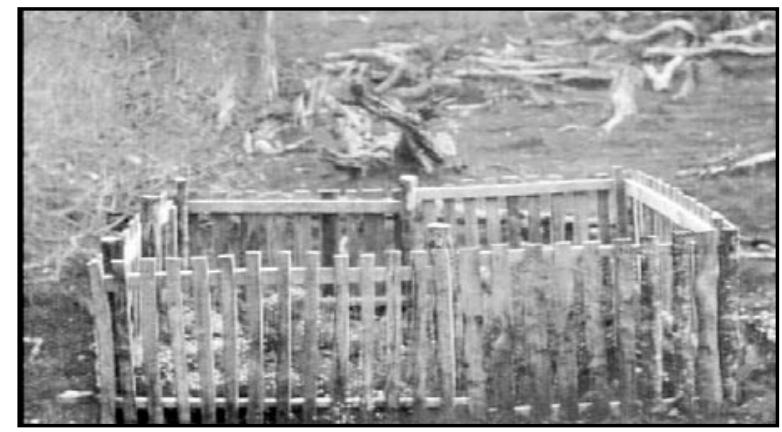

Fig. 7: Tumba próxima a las casas de la estancia "Vicuña" donde estaban sepultados los restos de indígenas sélknam fallecidos antes de la llegada de Auer.

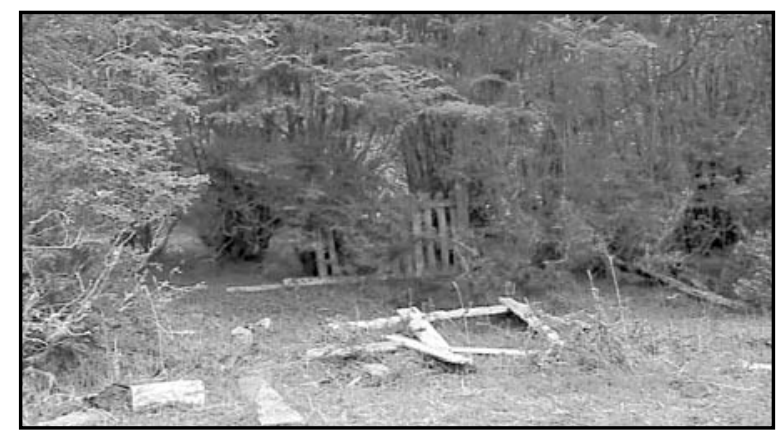

Fig. 8: Estado actual de la misma tumba (fotografía año 2004).

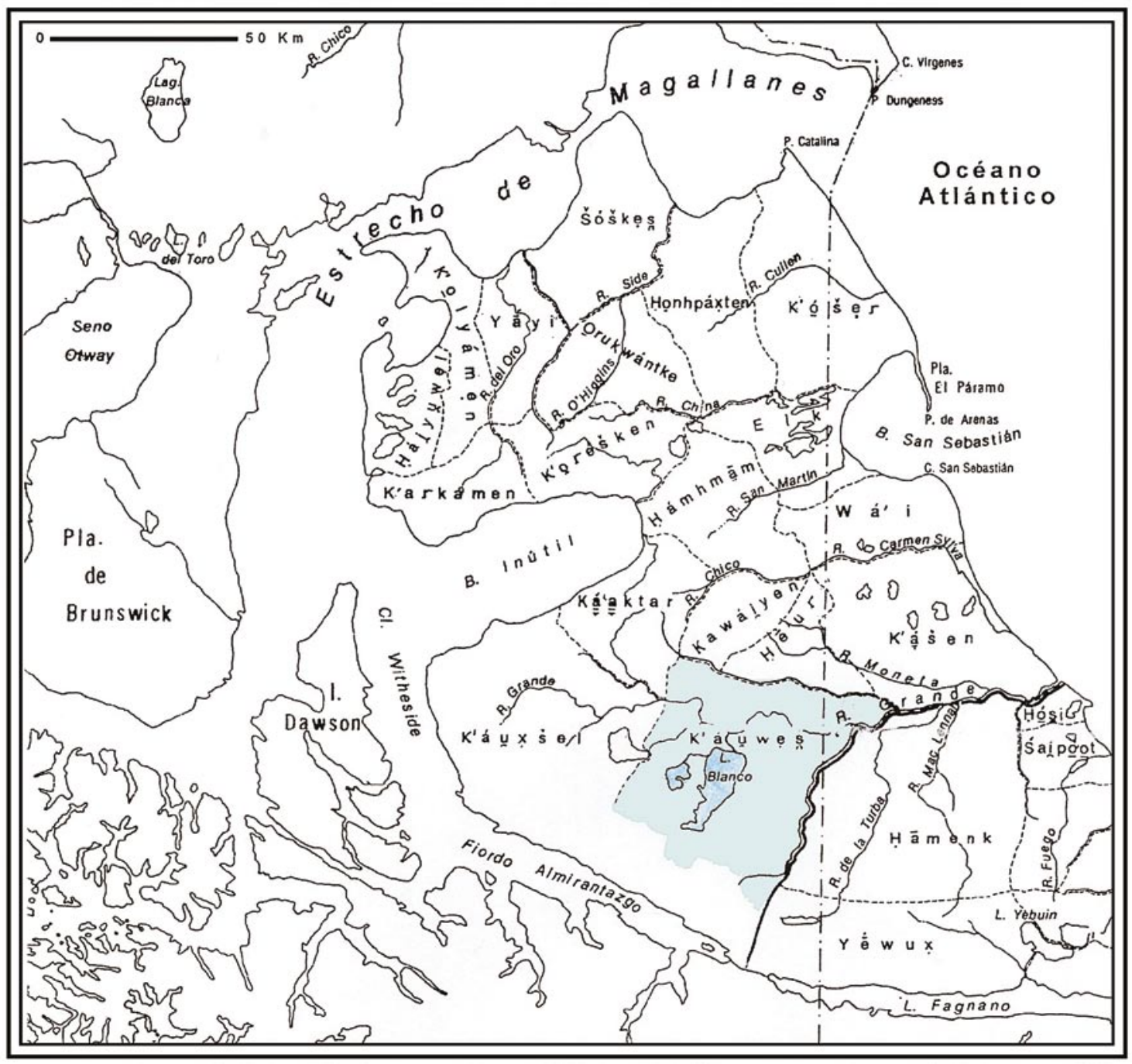

Fig. 9: Mapa etnográfico de territorios sélknam, adaptado de Gusinde (1982). En color gris se destaca el haruwen K'auwes. 
Ello nos lleva a conjeturar que tal vez para entonces los componentes del grupo pudieran haber superado en alguna medida el tremendo trauma anímico que hubo de significar para ellos el triste destino final de la etnia sélknam, y su obligada existencia entre foráneos, adoptando, siquiera en el habitar y en el vestir, las formas propias de aquéllos. Cualquiera que sea la interpretación que pueda darse a estos documentos fotográficos, no cabe dudar de su valor testimonial.

Mientras no dispongamos de la traducción del texto con el que Auer pudo explicar tal presencia aborigen en la estancia "Vicuña", aunque señala que Freily trabajaba para la misma ${ }^{2}$, no tendremos razón satisfactoria para entenderla. Sin embargo, puede conjeturarse que, o bien se trató de gente que vivía en ese y otros lugares aledaños con antelación al comienzo del establecimiento (aproximadamente hacia 1915), o que habría sido un grupo que arribó con posterioridad a tal circunstancia y fue acogido por la administración de la estancia. Pero, como haya sido, no cabe duda, se reitera, de que disponemos de la evidencia que permite confirmar que para 1929 e indeterminados tiempos anterior y posterior, la supervivencia sélknam en un paraje de su territorio ancestral, hoy suelo chileno. En abono de la suposición de una presencia anterior está el registro de una sepultura, hecho por Auer o alguien de su grupo, de una tumba situada, según parece, en las inmediaciones del casco de la estancia "Vicuña", en que se encontraban los cuerpos de otros indígenas (Fig. 7), sepultura cuyos restos fueron igualmente fotografiados por los periodistas finlandeses mencionados (Fig. 8). Tal circunstancia, la sepultación, nos afirma en la creencia de que en la comunidad sélknam de Vicuña pudo haber una permanencia temporal prolongada, con una clara voluntad de arraigo en su suelo ancestral.

Queda por ver si el grupo retratado y quizá los otros indígenas a los que hiciéramos referencia precedentemente, pudieron ser los sobrevivientes titulares tradicionales de los haruwen ubicados en el sector boscoso centro-sur de la isla grande de Tierra del Fuego, o bien, el relicto de la dispersión y reconcentración forzadas que impusiera la ocupación colonizadora ganadera.

El arqueólogo Mauricio Massone, en uno de sus ultimos trabajos (2003), incluye un mapa con información sobre los haruwen adaptada de Martín
Gusinde (Fig. 9). Allí se puede observar que en lo que más tarde fueron terrenos de la concesión de la Sociedad Ganadera e Industrial de Magallanes (Estancia "Vicuña"), se habían ubicado dos distritos identificados como K'auxsel, el occidental, y K'áuwes, el oriental.

Respecto de la segunda posibilidad enunciada, viene al caso agregar un antecedente hasta ahora virtualmente desconocido. Se trata de la información rescatada de el diario El Magallanes de Punta Arenas (entonces un semanario), en sus ediciones correspondientes a los días 20 de enero y 3 de febrero de 1895, y que da cuenta de un incidente ocurrido a los miembros de la Comisión Argentina de Límites en la zona de la costa norte del lago Fagnano, que (con aquellos de la correspondiente chilena) se ocuparan de erigir los hitos a lo largo de la línea demarcatoria internacional. Sucedió que el campamento utilizado por ellos fue saqueado por los sélknam que habitaban por ese paraje. Agrega textualmente la parte final de la información correspondiente al día 3 de febrero, que Los onas se vieron obligados a viajar a la parte más meridional del sector, debido a los establecimientos ganaderos.

Surge así otra posibilidad de investigación que podría permitir encontrar nuevos antecedentes acerca de qué grupos de la etnia sélknam pudieron habitar en los distritos o haruwen de la parte central-sur de la Tierra del Fuego en actual jurisdicción nacional.

Queda, por fin, otra investigación abierta, como continuidad del presente artículo y del precedente citado, para rastrear hasta donde sea posible el destino final de los últimos sobrevivientes sélknam en el territorio fueguino chileno.

\section{FUENTES DE CONSULTA}

ALHONEN, PENTTI \& ANTERO ALHONEN 2006 Vaakavaren Ratsastaja. Helsinki.

AUER, VÄINÖ, 1929 Tulimaata tutkimassa. Otava, Helsinki. MARTINIC B. MATEO 2003. Los últimos sélknam en Tierra del Fuego. Magallania. 31: 21-31. Punta Arenas.

MASSONE, MAURICIO Y OTROS 2003. Sitios arqueológicos, restos de cetáceos y territorios locales selk'nam en Tierra del Fuego. Magallania. 31: 45-59. Punta Arenas.

PIELA, MIKKO Y TAHAVO IRVONEN 2005 Väinö Auer, documental cinematográfico. Helsinki. 